\title{
Evaluation of SHOX copy number variations in patients with Müllerian aplasia
}

Maria Sandbacka ${ }^{1,2^{*}}$, Mervi Halttunen ${ }^{3}$, Varpu Jokimaa ${ }^{4}$, Kristiina Aittomäki ${ }^{1,5}$ and Hannele Laivuori ${ }^{2,6}$

\begin{abstract}
Background: Müllerian aplasia (MA) characterized by congenital loss of functional uterus and vagina is one of the most difficult disorders of female reproductive health. Despite of growing interest in this research field, the cause of the disorder for the majority of patients is still unknown. A recent report of partial SHOX duplications in five patients with MA has motivated us to further evaluate their role in the disorder. Therefore we have studied SHOX copy number variations (CNVs) in a cohort of 101 Finnish patients with MA and in 115 healthy controls.

Methods: We used multiplex ligation-dependent probe amplification (MLPA) to study SHOX CNVs.

Results: All patients showed normal amplification of SHOX. Several aberrations, duplications and deletions, were found downstream of the gene in five patients and seven controls, but these were all copy number polymorphisms.

Conclusions: Our study in an extensive cohort of patients with MA does not support a role for SHOX CNVs in the aetiology of the disorder. Further studies in the field are important for both patients looking for answers as well as for the scientific community for better understanding the regulation of the female reproductive duct development.
\end{abstract}

\section{Background}

The Müllerian ducts form the primordial basis for the female reproductive tract. They differentiate into the oviducts, uterus, and the upper two-thirds of the vagina during early embryonic development. A wide variety of malformations can occur if this development is disrupted. One such malformation is Müllerian aplasia (MA), also referred to as Mayer-Rokitansky-Küster-Hauser $(\mathrm{MRKH}$, Online Mendelian Inheritance in Man [OMIM] \#277000) syndrome or MURCS assosciation (Müllerian duct aplasia, Renal dysplasia and Cervical Somite anomalies, OMIM \#601076) as renal and skeletal malformations are relatively common in patients with MA [1]. Women with MA are otherwise healthy with normal female chromosome constitution (46, XX) and normal secondary sexual characteristics. MA is commonly diagnosed in young adulthood due to primary amenorrhoea. The effects on sexual life with infertility often cause lifelong psychosocial problems making MA one of the most difficult disorders of female reproductive health. The minimum incidence of MA is 1 in 5000

\footnotetext{
* Correspondence: maria.sandbacka@helsinki.fi

${ }^{1}$ Folkhälsan Institute of Genetics, Helsinki, Finland

Full list of author information is available at the end of the article
}

newborn girls [2], and for the majority of the patients the cause is still unknown.

During recent years, an increasing number of studies have aimed at investigating the genetic basis of MA. To date, only mutations in WNT4 (the wingless-type MMTV integration site family, member 4 gene) have been reported to cause MA [3-6]. However, the phenotype of the four patients with WNT4 mutations includes hyperandrogenism, which usually is not associated with MA, suggesting that these patients form a distinct subclass of MA (OMIM \#158330). Several other candidate genes involved in fetal development and sex differentiation have been thoroughly investigated without further success as reviewed by Sultan and colleagues [7].

Chromosomal imbalances studied by array comparative genomic hybridization ( $\mathrm{aCGH}$ ) have been reported for several chromosomal areas in MA patients [8-14]. However, as these are located in several different locations along the genome $(1 \mathrm{q} 21.1,16 \mathrm{p} 11.2,17 \mathrm{q} 12$, $22 \mathrm{q} 11.2$ and $\mathrm{Xq} 21.31$ ), they have not revealed strong candidate regions or genes for MA. Interestingly, partial duplications of SHOX (short stature homeobox gene) were recently reported in five patients (two sporadic, three familial) with MA [15]. In one family, the same
C Biomed Central

(c) 2011 Sandbacka et al; licensee BioMed Central Ltd. This is an Open Access article distributed under the terms of the Creative Commons Attribution License (http://creativecommons.org/licenses/by/2.0), which permits unrestricted use, distribution, and reproduction in any medium, provided the original work is properly cited. 
duplication was present in two sisters with MA and their healthy father, but absent in two healthy sisters and their mother suggesting a dominant inheritance of MA from an unaffected male carrier.

SHOX is a homeobox gene covering $40 \mathrm{~kb}$ on the pseudoautosomal region (PAR1) of the X (Xp22) and $\mathrm{Y}$ (Yp11.3) chromosomes. Like other genes within the PAR1, SHOX escapes $\mathrm{X}$ inactivation and therefore both alleles are normally expressed in males and females. Mutations and deletions in SHOX have been reported to cause short stature in patients with idiopathic short stature (ISS, OMIM \#300582), Turner syndrome [16,17], dyschondrosteosis (Leri-Weill syndrome, LWD, OMIM \# 127300) [18] and its more severe form Langer mesomelic dysplasia (OMIM \#249700) [19]. Recently, some patients with ISS and LWD have been reported to carry duplications of $S H O X /$ PAR1 region [20].

To further evaluate the role of $S H O X$ in MA, we have studied SHOX with MLPA (multiplex ligation-dependent probe amplification) in a cohort of 101 Finnish patients with MA and 115 healthy female controls.

\section{Patients and methods}

Patients

Patients with MA were recruited to the study through the Departments of Obstetrics and Gynecology of the five University Hospitals in Finland from year 1978 onwards. The cohort included 101 Finnish patients, of whom two are siblings. The clinical phenotype of all patients includes congenital loss of the uterus and the upper twothirds of the vagina, while the status of the oviducts is not known for all patients. The patients were otherwise healthy females with a normal female chromosome constitution, hormonally active functioning ovaries, and normal secondary sexual characteristics. One hundred and fifteen women with at least one normal pregnancy served as controls. Informed consent was obtained from all patients and controls before recruitment. The study protocol has been approved by the Ethics Committee of the Department of Obstetrics and Gynecology, Helsinki University Central Hospital, Finland, and the Finnish Ministry of Social Affairs and Health.

\section{Sample preparation}

DNA from the patients and controls was extracted from peripheral blood samples using the Puregene DNA Isolation Kit (Gentra Systems, Minneapolis, MN, USA), or by the phenol-chloroform method. The quality and quantity of DNA was analyzed by NanoDrop ND-1000 spectrophotometer (Thermo Fisher Scientific, Waltham, MA, USA).

Multiplex ligation-dependent probe amplification (MLPA) The commercial SALSA MLPA kit PO18-E1 SHOX (MRC-Holland, Amsterdam, Netherlands) was used for the amplification reactions according to the manufacturer's recommendation. The MLPA mix included probes for each exon of $S H O X$, one probe just before the promoter region as well as probes covering a region downstream of the gene. In short, 100 or $200 \mathrm{ng}$ of DNA was denatured and incubated with the MLPA probes for $16-18 \mathrm{~h}$ in $60^{\circ} \mathrm{C}$. The probes were ligated to the DNA and amplified by PCR. Thereafter, the PCR products were visualized on an agarose gel (1.5\%, Bioline, London, UK), appropriately diluted and combined with 1\% formamide (Applied Biosystems, Foster City, CA, USA) and GeneScan ${ }^{\mathrm{TM}}-500$ LIZ $^{\mathrm{TM}}$ size standard (Applied Biosystems). The products were then separated by capillary electrophoresis on an ABI3730XL DNA Analyzer (Applied Biosystems). The results were analyzed by GeneMapper software version 4.0 (Applied Biosystems) and MRC Coffalyzer MLPA-Dat Software (MRC-Holland). The results were also verified by the following calculation. Each peak area was divided by the sum of all peak areas, and the quotient was further divided by the sum of all peak areas of the reference sample. A reduction or increase of $40 \%$ or more in peak area, when compared to normal controls, was taken as suggestive for an aberrant amplification. All aberrant results were confirmed by a second independent MLPA analysis.

\section{Results}

All investigated MA samples $(\mathrm{N}=101)$ showed normal amplification of SHOX by MLPA. Aberrant amplification of some probes downstream of SHOX was detected in five MA and seven control samples (examples of the MLPA results are presented in Figure 1). One patient sample and one control showed two copy number variations (CNVs), all others samples showed one aberration each. One larger duplication spanning eleven probes from 13296-L15336 in Xp22.32-PAR1 to 13911-L16505 in the CRLF2 gene (about $620 \mathrm{~kb}$ ) was seen in one control sample (Table 1).

\section{Discussion}

The recent findings of partial SHOX duplications in three familial and two sporadic cases of MA [15] has motivated us to evaluate their occurrence in a larger patient cohort. We investigated 101 well-characterized Finnish MA patients and 115 controls by the MLPA technique without identifying any SHOX aberrations that could be interpreted as causative. We did observe copy number changes in twelve samples (five patients, seven controls) downstream of SHOX (Table 1), a region known to be involved in the gene regulation $[21,22]$. However, these changes were all reported in the Database of Genomic Variants (DGV, http://projects.tcag.ca/ variation) and three of them by Gervasini et al. [15] as 


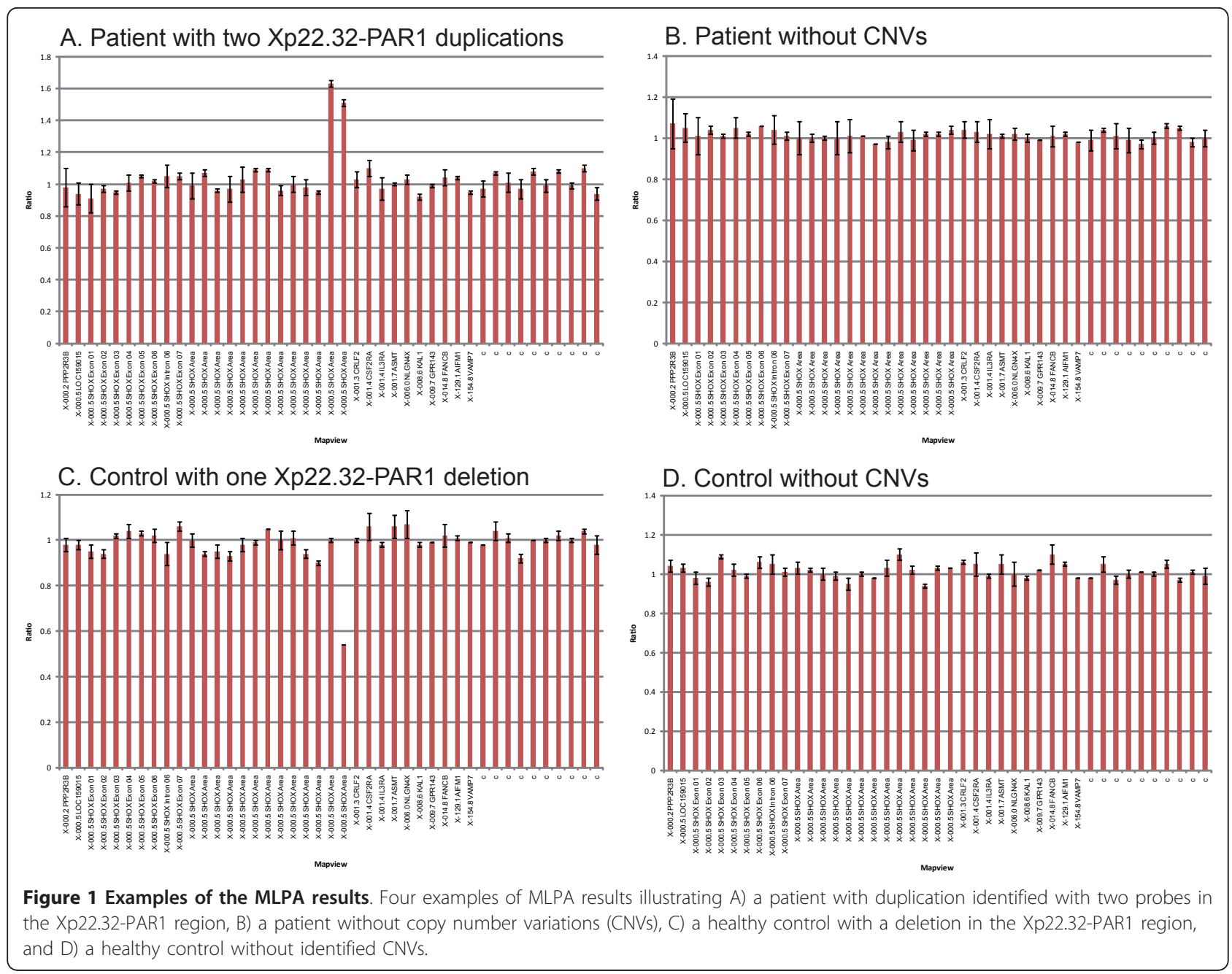

Table 1 Genomic aberrations found in patients with Müllerian aplasia and in healthy controls.

\begin{tabular}{|c|c|c|c|c|c|}
\hline Region/gene & Aberration & MLPA probe & Cases & Controls & Reference \\
\hline Xp22.32-PAR1 & Gain & $09335-L_{15508^{a}}$ & $1^{*}$ & $1^{*}$ & $\mathrm{DGV}^{b}$, Gervasini et al, 2010 \\
\hline Xp22.32-PAR1 & Loss & 09335-L15508 & 1 & 1 & DGV \\
\hline Xp22.32-PAR1 & Gain & $14697-L 16348^{a}$ & $1^{*}$ & $1^{*}$ & DGV, Gervasini et al, 2010 \\
\hline Xp22.32-PAR1 & Loss & 14697-L16348 & & 1 & DGV \\
\hline $\begin{array}{l}\text { Xp22.32-PAR1 } \\
\text { to CRLF2 }\end{array}$ & Gain & 13296-L15336 -13911-L16505 & & 1 & all 11 probes reported in DGV \\
\hline CSF2RA & Gain & 10251-L15502 & & 2 & DGV \\
\hline IL3RA & Gain & 13597-L15055 & 1 & & DGV \\
\hline ASMT & Gain & 01153-L00712 c & 2 & 1 & DGV, Gervasini et al, 2010 \\
\hline
\end{tabular}

Genomic aberrations found downstream of SHOX (short stature homeobox gene) by multiplex ligation-dependent probe amplification (MLPA, SALSA PO18-E1 SHOX) in 101 Finnish patients with Müllerian aplasia and in 115 healthy controls. One patient sample and one control sample had two copy number variations $(\mathrm{CNVs})^{*}$, all other samples had one CNV each.

${ }^{a}$ the probe sequence is partly overlapping with one MLPA probe (5650-L5104) from version PO18-B SHOX used by Gervasini et al, 2010.

${ }^{b}$ DGV (Database of Genomic Variants, http://projects.tcag.ca/variation)

${ }^{c}$ the probe sequence covers the same genomic region as one MLPA probe (1153-L0712) from version PO18-B SHOX used by Gervasini et al, 2010. 
harmless CNVs without phenotypic effect. A duplication 5 'of SHOX spanning about $620 \mathrm{~kb}$ from Xp22.32-PAR1 to the CRLF2 gene was found in one control sample. The entire duplication is not reported in DGV, but the genomic sequences of all eleven probes within the duplication are noted as known copy number variants.

In the study by Gervasini et al. 3/3 familial cases and $2 / 27$ sporadic cases (7\%) of MA showed partial duplications of SHOX. The clinical phenotype of these patients fulfills the same criteria as defined in our study cohort: absence of vagina and functional uterus in otherwise healthy females. If the inheritance of SHOX duplications in MA is dominant, as suggested, and based on abovementioned percentages we would expect several patients with SHOX duplications in the Finnish cohort (two sisters and seven of the sporadic patients). However, by implementing the same method as Gervasini and coworkers in a more than three times larger patient cohort, we did not find any aberrations in SHOX suggesting that $S H O X$ duplications are not a major cause of MA. Point mutations in SHOX resulting in a gain-of-function situation cannot, however, be excluded by the MLPA method.

Overall, duplications of the SHOX gene are rarely described in the literature. SHOX is thought to regulate human skeletal growth, and deletions of the gene to result in short stature (as in Turner syndrome) and an extra copy in tall stature (as in sex chromosome trisomies). The first case of SHOX duplication, not reported in conjunction with a larger chromosome aberration, was a female with isolated Madelung deformaties of the wrists. Interestingly, the duplication was also present in her healthy sister, making the clinical significance of the duplication unclear [23]. Subsequently, four more reports of patients with $S H O X$ duplications were published [20,24-26]. Unfortunately, the status of the uterus and vagina of the patients was not described in these reports. Furthermore, SHOX duplication in conjunction with chromosomal deletions on the long arm of X (Xq) has been reported in four females [27-30], one of whom had been reported with premature ovarian failure [30]. The authors suggested that the duplication in this patient could be involved in the ovarian insufficiency. The presence of uterus was described for three of the patients $[27,29,30]$, of whom one had experienced an early spontaneous abortion [30]. Unfortunately the status of uterus and vagina was not described in the fourth patient [28].

\section{Conclusions}

Taken together, there is no clear evidence in the literature for a role for SHOX in the development of the female reproductive duct. Secondly, our result based on an extensive series of Finnish patient samples does not support SHOX duplications as a frequent cause of MA. Finally, the duplications of SHOX found by Gervasini and co-workers [15] in combination with MA can be coincidental and may not be a reflection of an underlying genetic relationship. However, the aetiology of MA points to multifactorial inheritance. Partial duplications of SHOX might therefore be one of several genetic causes that contribute to the development of MA. Population genetic differences could explain why no duplications of SHOX were found in the Finnish cohort compared to the Italian. Furthermore, the possibility of point mutations in SHOX resulting in a gain-of-function situation cannot be excluded in our study.

Further studies aiming at revealing the genetic and molecular background of MA are important for both patients looking for an explanation for their symptoms as well as for the scientific community. Understanding the molecular basis of MA will be critical in increasing our knowledge for the regulation of the female reproductive tract development.

\section{Acknowledgements}

We acknowledge MD, Ph.D Pauli Kajanoja and MD Minna Puhakka for their contribution in the MA project in Finland. The authors are sincerely grateful to the patients and control persons, who have participated in the study. This work was supported by the Victoria Foundation and Samfundet Folkhälsan in Finland.

\section{Author details}

${ }^{1}$ Folkhälsan Institute of Genetics, Helsinki, Finland. ${ }^{2}$ Department of Medical Genetics, Haartman Institute, University of Helsinki, Helsinki, Finland. ${ }^{3}$ Department of Obstetrics and Gynecology, Helsinki University Central Hospital, Helsinki, Finland. ${ }^{4}$ Department of Obstetrics and Gynecology, University of Turku, Turku, Finland. ${ }^{5}$ Department of Clinical Genetics, Helsinki University Central Hospital, Helsinki, Finland. ${ }^{6}$ Research Programs Unit, Women's Health, University of Helsinki, Helsinki, Finland.

\section{Authors' contributions}

MS: project design, laboratory work and result analysis, manuscript preparation.

MH: clinician examining and enrolling patients in the study, manuscript preparation.

VJ: clinician examining and enrolling patients in the study, manuscript preparation.

KA: principal investigator, project design, result analysis, manuscript preparation.

HL: senior investigator, project design, result analysis, manuscript preparation. All authors read and approved the final manuscript.

\section{Competing interests}

The authors declare that they have no competing interests.

Received: 28 April 2011 Accepted: 2 August 2011

Published: 2 August 2011

\section{References}

1. Griffin JE, Edwards C, Madden JD, Harrod MJ, Wilson JD: Congenital absence of the vagina. The Mayer-Rokitansky-Kuster-Hauser syndrome. Ann Intern Med 1976, 85:224-36.

2. Aittomäki $K$, Eroila $H$, Kajanoja P: A population-based study of the incidence of Müllerian aplasia in Finland. Fertil Steril 2001, 76:624-5. 
3. Biason-Lauber A, Konrad D, Navratil F, Schoenle EJ: A WNT4 mutation associated with Müllerian-duct regression and virilization in a 46, XX woman. N Engl J Med 2004, 351:792-8.

4. Biason-Lauber A, De Filippo G, Konrad D, Scarano G, Nazzaro A, Schoenle EJ: WNT4 deficiency-a clinical phenotype distinct from the classic Mayer-Rokitansky-Kuster-Hauser syndrome: a case report. Hum Reprod 2007, 22:224-9.

5. Philibert P, Biason-Lauber A, Rouzier R, Pienkowski C, Paris F, Konrad D, et al: Identification and functional analysis of a new WNT4 gene mutation among 28 adolescent girls with primary amenorrhea and mullerian duct abnormalities: a French collaborative study. J Clin Endocrinol Metab 2008, 93:895-900.

6. Philibert P, Biason-Lauber A, Gueorguieva I, Stuckens C, Pienkowski C, Lebon-Labich B, et al: Molecular analysis of WNT4 gene in four adolescent girls with mullerian duct abnormality and hyperandrogenism (atypical Mayer-Rokitansky-Kuster-Hauser syndrome). Fertil Steril 2011, 95:2683-6.

7. Sultan C, Biason-Lauber A, Philibert P: Mayer-Rokitansky-Kuster-Hauser syndrome: recent clinical and genetic findings. Gynecol Endocrinol 2009, 25:8-11.

8. Cheroki C, Krepischi-Santos AC, Rosenberg C, Jehee FS, Mingroni-Netto RC, Pavanello Filho I, et al: Report of a del22q11 in a patient with MayerRokitansky-Küster-Hauser (MRKH) anomaly and exclusion of WNT-4, RARgamma, and RXR-alpha as major genes determining MRKH anomaly in a study of 25 affected women. Am J Med Genet A 2006, 140:1339-42.

9. Bendavid C, Pasquier L, Watrin T, Morcel K, Lucas J, Gicquel I, et al: Phenotypic variability of a $4 q 34->$ qter inherited deletion: MRKH syndrome in the daughter, cardiac defect and Fallopian tube cancer in the mother. Eur J Med Genet 2007, 50:66-72.

10. Sundaram UT, MCDonald-McGinn DM, Huff D, Emanuel BS, Zackai EH, Driscoll DA, et al: Primary amenorrhea and absent uterus in the 22q11.2 deletion syndrome. Am J Med Genet A 2007, 143A:2016-8.

11. Cheroki C, Krepischi-Santos AC, Szuhai K, Brenner V, Kim CA, Otto PA, et al: Genomic imbalances associated with mullerian aplasia. J Med Genet 2008, 45:228-32.

12. Bernardini L, Gimelli S, Gervasini C, Carella M, Baban A, Frontino G, et al: Recurrent microdeletion at 17q12 as a cause of Mayer-RokitanskyKuster-Hauser (MRKH) syndrome: two case reports. Orphanet J Rare Dis 2009, 4:25

13. Ledig S, Schippert C, Strick R, Beckmann MW, Oppelt PG, Wieacker P: Recurrent aberrations identified by array-CGH in patients with MayerRokitansky-Küster-Hauser syndrome. Fertil Steril 2011, 95:1589-94.

14. Nik-Zainal S, Strick R, Storer M, Huang N, Rad R, Willatt L, et al: High incidence of recurrent copy number variants in patients with isolated and syndromic Mullerian aplasia. J Med Genet 2011, 48:197-204.

15. Gervasini C, Grati FR, Lalatta F, Tabano S, Gentilin B, Colapietro P, et al: SHOX duplications found in some cases with type I Mayer-RokitanskyKuster-Hauser syndrome. Genet Med 2010, 12:634-40.

16. Rao E, Weiss B, Fukami M, Rump A, Niesler B, Mertz A, et al: Pseudoautosomal deletions encompassing a novel homeobox gene cause growth failure in idiopathic short stature and Turner syndrome. Nat Genet 1997, 16:54-63.

17. Ellison JW, Wardak Z, Young MF, Gehron Robey P, Laig-Webster M, Chiong W: PHOG, a candidate gene for involvement in the short stature of Turner syndrome. Hum Mol Genet 1997, 6:1341-7.

18. Belin V, Cusin V, Viot G, Girlich D, Toutain A, Moncla A, et al: SHOX mutations in dyschondrosteosis (Leri-Weill syndrome). Nat Genet 1998, 19:67-9.

19. Shears DJ, Vassal HJ, Goodman FR, Palmer RW, Reardon W, Superti-Furga A, et al: Mutation and deletion of the pseudoautosomal gene SHOX cause Leri-Weill dyschondrosteosis. Nat Genet 1998, 19:70-3.

20. Benito-Sanz S, Barroso E, Heine-Suñer D, Hisado-Oliva A, Romanelli V, Rosell J, et al: Clinical and molecular evaluation of SHOX/PAR1 duplications in Leri-Weill dyschondrosteosis (LWD) and idiopathic short stature (ISS). J Clin Endocrinol Metab 2011, 96:E404-12.

21. Benito-Sanz S, Thomas NS, Huber C, Gorbenko del Blanco D, AzaCarmona M, Crolla JA, et al: A novel class of Pseudoautosomal region 1 deletions downstream of SHOX is associated with Leri-Weill dyschondrosteosis. Am J Hum Genet 2005, 77:533-44.

22. Fukami M, Kato F, Tajima T, Yokoya S, Ogata T: Transactivation function of an approximately 800-bp evolutionarily conserved sequence at the
SHOX 3 ' region: implication for the downstream enhancer. Am J Hum Genet 2006, 78:167-70

23. Grigelioniene G, Schoumans J, Neumeyer L, Ivarsson A, Eklof O, Enkvist O, et al: Analysis of short stature homeobox-containing gene (SHOX) and auxological phenotype in dyschondrosteosis and isolated Madelung deformity. Hum Genet 2001, 109:551-8.

24. Thomas NS, Harvey JF, Bunyan DJ, Rankin J, Grigelioniene G, Bruno DL, et al: Clinical and molecular characterization of duplications encompassing the human SHOX gene reveal a variable effect on stature. Am J Med Genet A 2009, 149A:1407-14.

25. Roos $L$, Brondum Nielsen $K$, Tümer $Z$ : A duplication encompassing the SHOX gene and the downstream evolutionarily conserved sequences. Am J Med Genet A 2009, 149A:2900-1.

26. D'haene B, Hellemans J, Craen M, De Schepper J, Devriendt K, Fryns JP, et al: Improved molecular diagnostics of idiopathic short stature and allied disorders: quantitative polymerase chain reaction-based copy number profiling of SHOX and pseudoautosomal region 1. J Clin Endocrinol Metab 2010, 95:3010-8.

27. Leppig KA, Brown CJ, Bressler SL, Gustashaw K, Pagon RA, Willard HF, et al: Mapping of the distal boundary of the $\mathrm{X}$-inactivation center in a rearranged $X$ chromosome from a female expressing XIST. Hum $\mathrm{Mol}$ Genet 1993, 2:883-7.

28. Ogata T, Matsuo N, Fukushima Y, Saito M, Nose O, Miharu N, et al: FISH analysis for apparently simple terminal deletions of the $X$ chromosome identification of hidden structural abnormalities. Am J Med Genet 2001, 104:307-11.

29. Adamson KA, Cross I, Batch JA, Rappold GA, Glass IA, Ball SG: Trisomy of the short stature homeobox-containing gene (SHOX), resulting from a duplication-deletion of the X chromosome. Clin Endocrinol (Oxf) 2002, 56:671-5.

30. Tachdjian G, Aboura A, Portnoï MF, Pasquier M, Bourcigaux N, Simon T, et al: Cryptic Xp duplication including the SHOX gene in a woman with 46, X, del $(X)(q 21.31)$ and premature ovarian failure. Hum Reprod 2008, 23:222-6.

doi:10.1186/1750-1172-6-53

Cite this article as: Sandbacka et al:: Evaluation of SHOX copy number variations in patients with Müllerian aplasia. Orphanet Journal of Rare Diseases 2011 6:53.

\section{Submit your next manuscript to BioMed Central and take full advantage of:}

- Convenient online submission

- Thorough peer review

- No space constraints or color figure charges

- Immediate publication on acceptance

- Inclusion in PubMed, CAS, Scopus and Google Scholar

- Research which is freely available for redistribution

Submit your manuscript at www.biomedcentral.com/submit
C Biomed Central 